Research Article

\title{
Simulation and Experiment of a Kind of Thin-Walled Tube Crushing Member Used for Antiimpact Column
}

\author{
Cheng-long Wang, Yifang Chen, QingLiang Zeng $\mathbb{i}$, and Guoming Liu $\mathbb{i}$ \\ Shandong University of Science and Technology, Qingdao 266590, China \\ Correspondence should be addressed to QingLiang Zeng; qlzeng@163.com and Guoming Liu; skd995978@sdust.edu.cn
}

Received 31 December 2020; Revised 15 March 2021; Accepted 8 April 2021; Published 17 May 2021

Academic Editor: Rodrigo Nicoletti

Copyright ( $\odot 2021$ Cheng-long Wang et al. This is an open access article distributed under the Creative Commons Attribution License, which permits unrestricted use, distribution, and reproduction in any medium, provided the original work is properly cited.

\begin{abstract}
In order to solve the problem of poor antiimpact ability of hydraulic support under rock bursting, a kind of thin-walled cylinder crushing component used in the composite spiral antiimpact device was developed, and different structural models were proposed and simulated. On this basis, the model was verified by experiments. The results show that the arrangement of the hollow structure can restrain the ring mode deformation and Euler instability of the tube member in the crushing yield and can carry out the buckling deformation according to the expected crushing force during the compression deformation process and effectively reduce the initial peak force. The arrangement of guide grooves can make the buckling deformation more stable and regular, which can effectively reduce the initial peak force and elastic displacement. With the smaller wall thickness and the smaller wall thickness of the induced groove, the effective deformation yield stroke of the crushing member increases, and the initial peak force, total energy absorption, average reaction force, and elastic displacement decrease. The simulation results are consistent with the experimental results which will be used in the future works.
\end{abstract}

\section{Introduction}

In recent years, rock burst accidents in coal mines occurred frequently, which has become the main disaster of deep mining in China [1-3]. Hydraulic supports are the main roadway support equipment for coal mining. Some highstrength hydraulic supports are gradually used to increase the support strength to deal with rock bursts $[4,5]$. At the moment of the occurrence of rock burst, the surrounding rock pressure surges instantly, and the safety valve of the hydraulic support is often too late to be opened for pressure relief protection. In such condition, the support works in a rigid way. The pressure will directly cause the deformation and damage of the support, the column bends, the cylinder bursts, and damage to the guide sleeve [6], which led to the instability and destruction of the entire support system, resulting in equipment damage and casualties. Therefore, the development of a new type of hydraulic column with fast dynamic yielding and energy absorption ability is very necessary so as to enhance the antiimpact ability of roadway hydraulic support equipment and prevent roadway rock burst accident.

In order to improve the antiimpact performance of the support, Tang and Yang et al. $[7,8]$ provided a solution which is mainly performed by means of changing the structure of the support and adding energy-absorbing components to the support. However, in this solution, the thin-walled tube is easy to crack, the deformation mode is unstable, and the guide device needs to be set. The structure is complex, and the deformation energy absorption process requires high precision, which is difficult to be applied to the complex and severe actual impact conditions. Pan et al. [9] put forward a kind of energy dissipation buffer device for foamed aluminum, which depends on the energy absorption of aluminum foam. But the structure of such device is more complex, whose supporting ability under static pressure and 
the ability of energy absorption and impact prevention are relatively weak. Ma and Tang et al. $[10,11]$ put forward the different plate inclination angle of the corrugated tube and the thin-walled tube type energy-absorbing and antiimpact components with precrease. The precrease of such components needs special mold processing, the process is complex, and the production cost is high.

Aiming to reduce the peak load and the initial mean crushing strength stability problems, in 2017, a number of circular arc grooves are alternately preset on the outer wall, inner wall, and inner and outer walls of the thin-walled round tube by Li [12]. Various design forms a thin groove, which shows that the groove on the inner wall has a greater effect on reducing the initial peak force than the groove on the outer wall. In 2018, Hosseini et al. [13] studied the influence of three geometric parameters of inner diameter, length and thin-wall thickness, layer orientation, reinforcing fiber, and the manufacturing process on the crushing characteristics of thin-walled composite cylinders. Montazeri et al. [14] analyzed the crushing mechanism of two types of thin-walled structures (porous pipes and grooved pipes) through simulation and experiment, and the plastic deformation of the thin-walled pipe is analyzed by means of opening grooves and holes at predetermined intervals along the pipe. In 2019, Shams et al. [15] proposed a new method to improve the energy absorption performance of thin-walled round tubes under quasistatic side loads through mold processing. Using molds and various blade-shaped indenters, a simple round tube was formed into four different types of prefabricated samples, and the preshaped samples are horizontally crushed between two rigid press plates for the flattening test. In 2020, Song et al. [16] by studying two typical structures (cornstalk and the reed) reported that 4 types of foam-filled thin-walled bionic structure, through dynamic drop weight and quasistatic compression, the energy absorption capacity, and deformation mode of the bionic structure are studied. Dong et al. [17] designed a kind of energy-absorbing and antiimpact anchor support member, which achieves the energy-absorbing effect through the axial tearing and curling deformation of the metal round tube, but the initial support strength of this kind of member is small and the metal. The tearing deformation of the round tube takes up a lot of space. Yao et al. [18] used simulation and experimental research to compare the energy absorption characteristics of the open area and the unopened area of the circular pipe, which showed that the average crushing force will decrease with the increase of the pipe wall thickness or the decrease of the hole radius. The number of holes or reducing the radius of the holes can increase the specific energy absorption. Li et al. [19] studied the influence of the type and quantity of induced structures on the axial crushing deformation mode, initial peak force, crushing force efficiency, and energy absorption capacity of thin-walled square tubes filled with aluminum foam. The test verifies the accuracy of the finite element model of the thin-walled square tube filled with aluminum foam. Yi et al. [20] studied the influence of the diaphragm structure and the induced structure on the energy absorption characteristics, and it is concluded that the structure produces more buckling folds under the restriction of the diaphragm, and the energy absorption is increased.

In the process of collapse deformation of ordinary thinwalled circular pipe under rock burst, there are some problems, such as unstable deformation, easy Euler instability, large initial peak force, difficult to deform quickly, and unable to yield quickly. In view of the above problems, a new type of a screw type antiimpact device [21] is designed as the yielding device of the antiimpact column, and a thin-walled tube crushing structure is designed in the hydraulic cavity of the new type of screw type hydraulic buffer. Under the impact pressure, the spiral hydraulic buffer and the thinwalled tube work together. Therefore, the collapse structure of thin-walled circular pipe needs to meet the requirements of high hydrostatic support capacity, easy to deform quickly and stably, and the initial peak force should not be too large. In order to design the collapse structure of thin-walled circular pipe which meets the requirements of the new spiral antiimpact device, a finite element model of the hollow structure of thin-walled circular pipe is established, the collapse buckling analysis of five kinds of components is carried out, and the ideal collapse component structure is determined. The simulation results are verified by experiments. The research results provide the model basis and experimental basis for future work.

\section{Requirements and Design of Thin-Walled Tube Collapse Components}

2.1. Performance Requirements and Evaluation Parameters of Collapse Members. The antiimpact character of the conventional hydraulic column depends on the characteristics of the safety valve. When the energy-loading rate of the strong impact load exceeds the relief rate of the safety valve, the liquid pressure in the column will still rise rapidly after the safety valve is opened. Moreover, it is also very common that the column will fail before the safety valve is opened.

In order to solve the problem of poor applicability and response speed of relief capacity of the safety valve to different external loads, a new type of spiral hydraulic buffer [21] is proposed, in which a thin-walled tube crushing structure is designed in the hydraulic cavity. With the case of static load, the thin-walled tube collapse structure provides the working resistance force for the new type of spiral hydraulic buffer. With the case of dynamic load, the component will deform timely when the impact load exceeds a certain threshold value, so as to provide guarantee for the timely opening of the safety valve. The ideal crushing component should meet the following requirements:

(1) Reasonable bearing capacity of peak crushing force: the component does not deform or deforms less before the surrounding rock pressure or impact force reaches the peak force, and the component begins to give way and deform when the surrounding rock impact force exceeds the peak force. The initial peak value $F_{\max }$ (buckling load) of the reaction force of the 
force-displacement curve in the deformation process of a crushed member is usually its deformation threshold [22], so $F_{\max }$ is required to meet the requirements of formula (1), where Fr is the working resistance of the column and $F_{b}$ is the impact damaging-load of the column and other components. According to the relevant China national standards, the peak bearing capacity of the energy-absorbing member is generally designed to be $1.2-1.5$ times of the working resistance of the column $[23,24]$.

$$
F_{r}<F_{\max }<F_{b}
$$

(2) The displacement should be small in the elastic deformation stage. It is necessary to shorten the stroke under initial peak load as much as possible to ensure that the initial elastic deformation stage occurs earlier in the process of component crushing and buckling deformation. Distance $L$ in the elastic deformation stage is used for evaluation, where $L$ is the corresponding deformation when the component is crushed to reach the initial peak load.

(3) A relative large effective deformation stroke is needed. The effective deformation yield stroke can be used to express the plastic deformation ability of the component. The deformation yield is meaningful when reaction force of the component is less than or equal to the initial peak force, and the effective deformation yield stroke $\delta$ is used for evaluation [25].

(4) The component has a constant reaction force during the crushing process. $F_{\text {mean }}$ is the average crushing force, which reflects the overall load level of the member. It is defined as

$$
F_{\text {mean }}=\frac{1}{\delta} \int_{0}^{\delta} F(s) d_{s} .
$$

(5) $E$ is the total absorption energy, which describes the energy absorbed in the process of buckling deformation of the component. It can ensure effective energy absorption and impact resistance ability of the component.

$$
E=\int_{0}^{\delta} F(s) d_{s} .
$$

(6) The stability of the load during the antishock process is high. In order to ensure the effective and stable buffer protection of the support system, the mean square deviation $\sigma$ of the supporting reaction force is used to reflect its fluctuation, which is in the plastic deformation stage during the buckling deformation process of the component.

$$
\sigma=\sqrt{\int_{\delta_{1}}^{\delta}\left(F(s)-F_{\text {mean }}\right)^{2} p(x) d(s)} .
$$

(7) No expanding to the surroundings and no occupy of other spaces after the components are compressed and deformed
2.2. Design of Thin-Walled Round Tube Crushing Components. In this study, the thin-walled round tube crushing components are used for the antiimpact column whose working resistance is $3600 \mathrm{KN}$. In order to facilitate the test, the working resistance of the antiimpact column is reduced by 500 times. And the test working resistance is $7.2 \mathrm{KN}, F_{b}=1.2$, and $F_{r}=8.64 \mathrm{KN}$. Five structural schemes for the thick thinwalled round tube crushing member are designed, whose structure is shown in Figure 1. For the thin-walled cylindrical, the total height of $110 \mathrm{~mm}$ and the outer diameter of $60 \mathrm{~mm}$, the detailed design information is given in Table 1. From YG-1to YG-5, it shows different schemes, and the assembly plan is shown in Figure 2.

\section{Simulation of Various Schemes of Thin- Walled Tube Crushing Member}

In this section, the axial impact simulation of thin-walled cylindrical members with different structures and different thickness of induced grooves is carried out, and the influence of different parameters on the buckling deformation process and energy absorption characteristics of thin-walled cylindrical members are analyzed.

3.1. Deformation Morphology of Crush Buckling. The finite element model of crushing buckling simulation for crushing member is shown in Figure 3. In this model, the friction coefficient is 0.25 , the material is aluminum 5083, the material density is $2660 \mathrm{~kg} / \mathrm{m}^{3}$, the elastic modulus is $70 \mathrm{GPa}$, and Poisson's ratio is 0.3 .

The buckling simulation analysis of five schemes of crush members with different structures and induced groove thickness under quasistatic load is carried out, and the buckling deformation form of the members is shown in Figure 4 .

It can be seen from Figure 4 that the ax symmetric mode deformation of the crushed member occurs at the initial stage of buckling deformation. As the crushed member continues to be crushed, its deformation is transformed into a non-ax symmetric deformation mode of buckling after reaching the initial peak force. In such cases, the deformation of the component is in the mixed mode [26-29].

According to the plastic strain distribution nephogram of the crushing member, it can be seen that the area with high stress is the area with large plastic deformation, and the stress and deformation of hollow crushing member are concentrated in the middle two-layer hollow. As the crushing member continues to be crushed, the hollow bending and folding will be together in the dense state.

3.2. Antishock Performance Parameters of Crushing Components. The reaction force-deformation curve of each component in the crushing and buckling process is shown in Figure 5 .

The reaction force-deformation curve of each scheme can be roughly divided into three stages:

(1) In the initial elastic deformation stage, the component is in a short-term elastic deformation state at the 

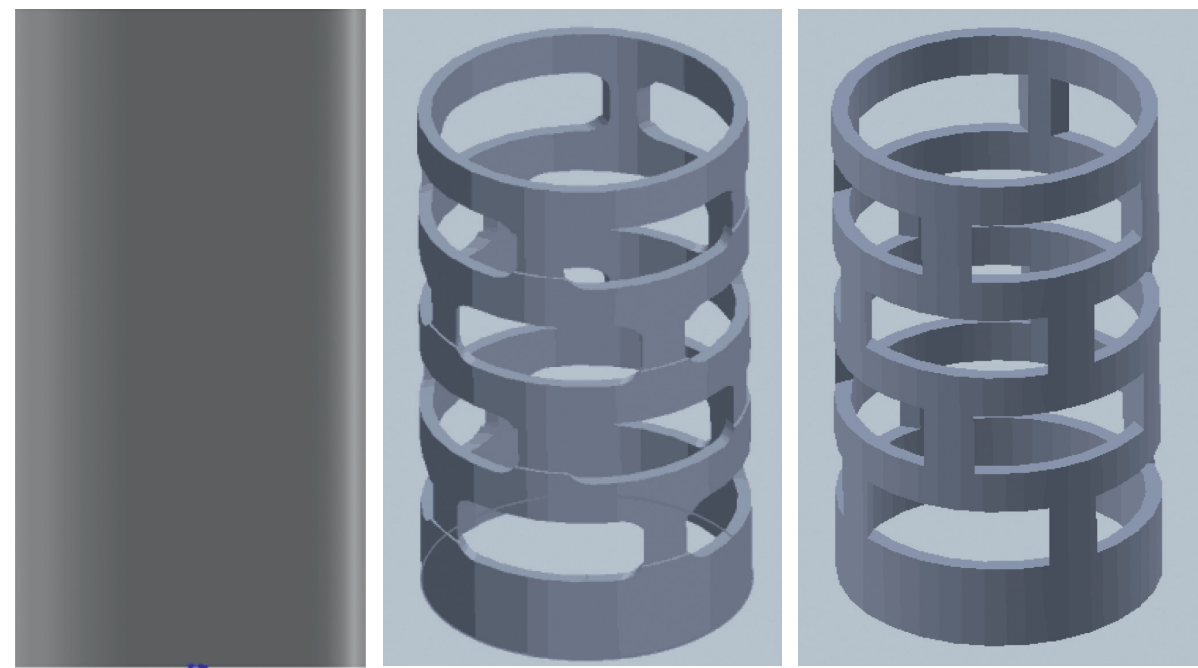

Figure 1: Three structural schemes of thin-walled round tube crushing components.

TABLE 1: Schemes of thin-walled energy-absorbing components.

\begin{tabular}{lccc}
\hline No. & Wall thickness $(\mathrm{mm})$ & Groove $(\mathrm{mm})$ & Structure \\
\hline YG-1 & 3 & No & Round tube \\
YG-2 & 3 & No & Hollow out \\
YG-3 & 2.5 & No & Hollow out \\
YG-4 & 3 & 2.5 & Hollow out \\
YG-5 & 2.5 & 2 & Hollow out \\
\hline
\end{tabular}

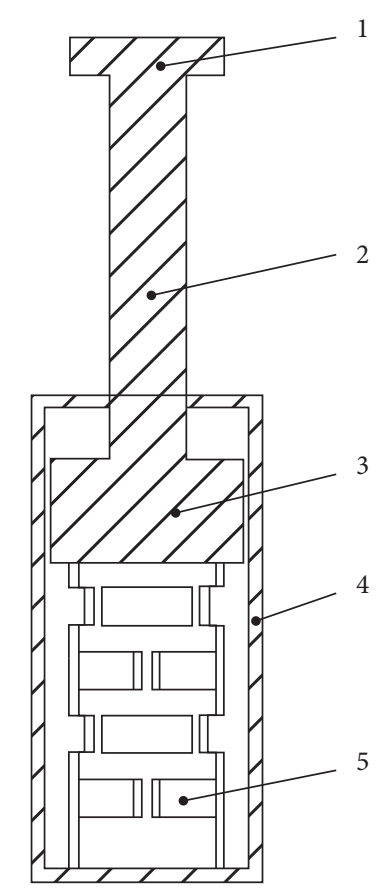

FIGURE 2: Installation plan of crushed components of thin-walled round pipe. (1) End cover, (2) piston rod, (3) piston, (4) cylinder body, (5) crushing parts.

beginning of crushing, and the supporting reaction force increases rapidly from zero to the initial peak force. (2) In the plastic deformation stage, after the initial peak value of the support reaction, the component begins to undergo large plastic deformation, forming bending folds and causing relatively continuous reaction force. (3) In the compaction 
stage, the component is crushed to a compact state, the reaction force quickly rises to the initial peak force, and the effective deformation yield stroke is ended.

The reaction force fluctuations of nonhollowed round tube members are relatively obvious in the plastic deformation stage. Generally speaking, for each different scheme, the smaller the thickness of the same structure, the lower the reaction force during crushing buckling. There are mainly two deformation forms during the plastic deformation process of component crushing and buckling, which are bending and stretching. The influence of structural thickness on the reaction force of bending and tensile deformation is positively correlated $[30,31]$. Therefore, the reduction of wall thickness can help to reduce the overall reaction force of members.

The initial peak force, displacement during the elastic stage, displacement of effective deformation, total absorbed energy, mean square deviation, and average support reaction force of each scheme are shown in Figure 6. The performance evaluation parameters of tubular members are given in Table 2.

From Figure 6(a) and Table 1, it shows that the initial peak force of hollow thin-walled circular tube crushing member is smaller than that of ordinary thin-walled circular tube crushing member under the condition of equal inner diameter and wall thickness, which indicates that the hollow structure makes the member more stable, regular, and can effectively help to reduce the initial peak force.

For hollow components, as the wall thickness is decreased, the initial peak force during crushing buckling and the average reaction force are smaller. The initial peak force of the thin-walled round tube crushing component with the induction groove is smaller than that of the ordinary hollow thin-walled round tube crushing component, which shows that the opening of the induction groove makes the component's crushing and buckling deformation more stable and regular and effectively reduces the initial peak force.

It can be seen from Figure 6(b) that the thickness reducing of the thin-walled round tube and arranging of the induction grooves can make the components more plastically deformable, effectively reduce the displacement in the elastic stage, and improve the response speed of the crushed components.

It can be seen from Figure 6(c) that the effective deformation yield stroke increases with the wall thickness decreasing and arranging of the induction groove. The bending folds formed by the collapse and buckling process of the component with the induction groove and the smaller wall thickness are smaller, and the material plastic deformation is sufficient. In such cases, the deformation is effective which give way to a larger yield stroke. On the contrary, if the wall thickness is large and the induced trough is not arranged, the plastic deformation is insufficient, the reaction force with large fluctuation will reach the initial peak force earlier, and the yield stroke is smaller.

It can be seen from Figures 6(d) and 6(e) that the decrease of wall thickness and the arrangement of induced grooves reduce the energy absorption of members. The energy absorption is affected by the reaction force and the effective displacement. The general decreasing trend of total energy absorption is mainly affected by the decreasing of reaction force. According to equations (2) and (3), the average support reaction is the ratio of the total energy absorption to the effective displacement, where the law of the average support reaction is greatly affected by the total energy absorption law.

It can be seen from Figure 6(f) that for the same structural member, as the wall thickness and the thickness of the induced groove decrease, the mean square error of the supporting reaction force basically decreases. The members with smaller wall thickness and induction groove thickness are more easily deformed during crushing buckling, and the bending folds formed are more and smaller. Therefore, the stability of the load during the antiimpact process is higher, the fluctuation is smaller, and the mean square error is smaller. In the process of crushing and buckling, the members with larger induced groove thickness are not easy to deform, and the bending folds formed are less and larger. Therefore, the stability of the load during the antishock process is lower, the fluctuation is larger, and the mean square error is larger.

\section{Experimental Analysis of Crushing Buckling Deformation of Thin-Walled Round Tube Crushing Components}

4.1. Compression and Buckling Deformation of Members. Five thin-walled members as shown in Figure 7 are manufactured, and the collapse buckling test is performed by means of an electronic universal testing machine, which is shown in Figure 8. The deformation morphology of each component in the crushing buckling test is shown in Figure 9. The main conclusion is as follows:

(1) Euler instability occurs due to crushing and buckling of round pipe members without hollow structure

(2) The outer diameter deformation of the hollow round pipe member without induction groove is large in crushing buckling

(3) The outer diameter deformation of the thin-walled round tube member with induction grooves is small, and the deformation is regular.

Compared with the buckling simulation analysis of the thin-walled crushed component in the ideal deformation pattern, irregular deflection and cracking happened in the test, which is due to the possible component structural material defects and nonideal test loading conditions during the test. For example, the thickness of the pipe wall and the induction groove of the component are not uniform; the eccentric error of the placement position of the component is impacted and crushed.

Compared with the hollow structure tube structure in component YG-1, the Euler instability occurs during the crushing and buckling deformation of the hollow structure tube structure. The hollow structure deformation is concentrated on the hollow vertical bars, resulting in larger 


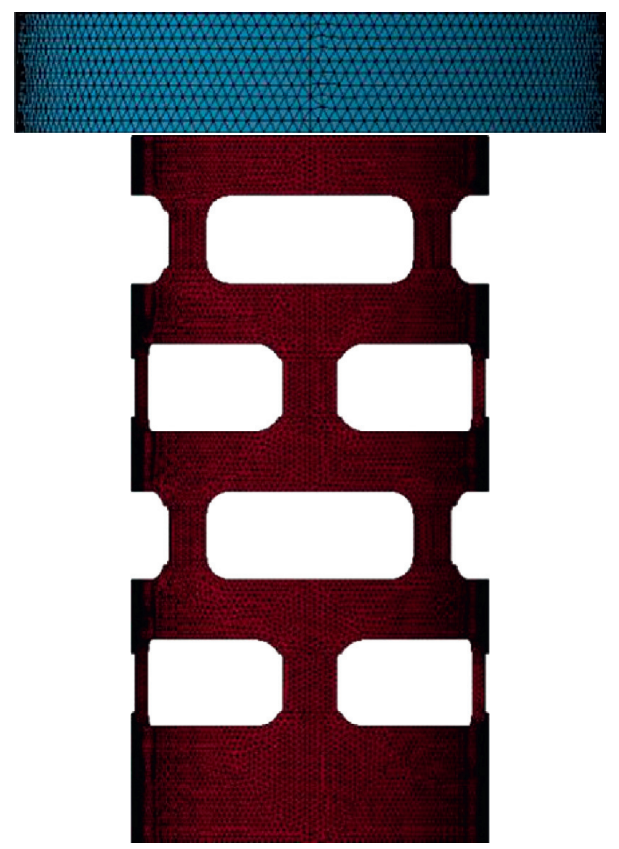

Figure 3: Finite element model of crushing buckling simulation for crushing member.

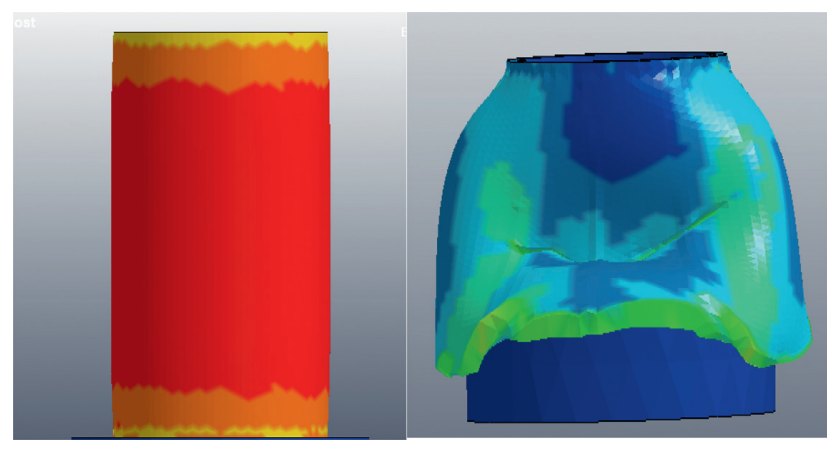

(a)
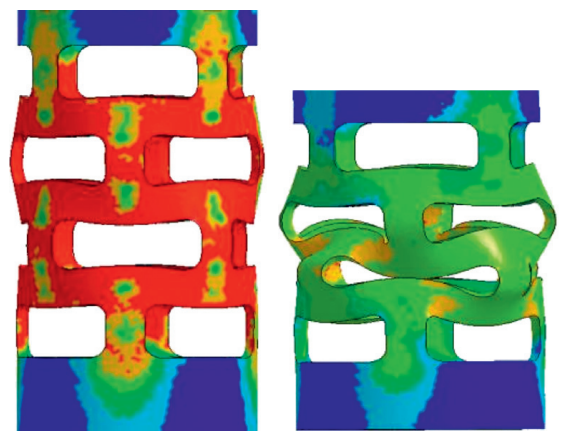

(c)
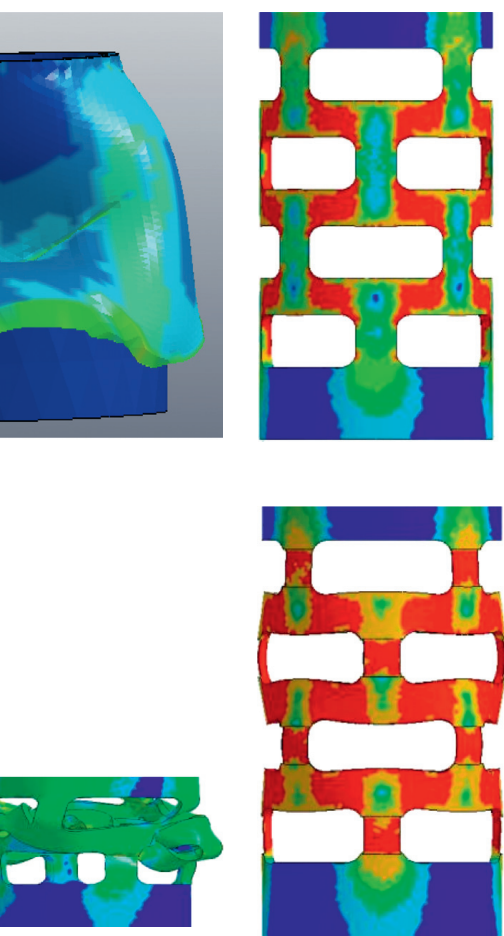

Figure 4: Continued.

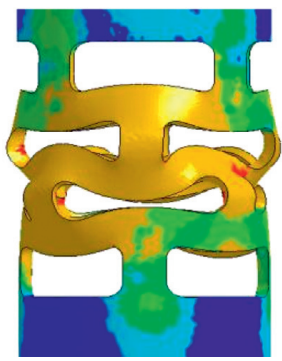

(b)

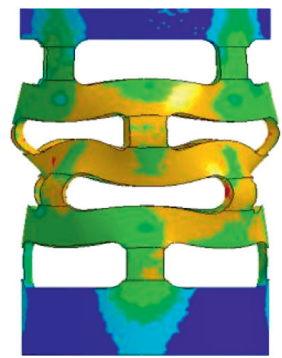

(d)
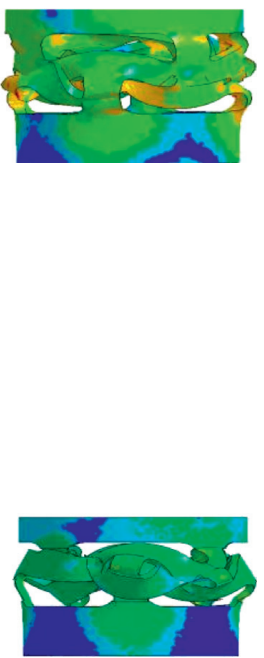

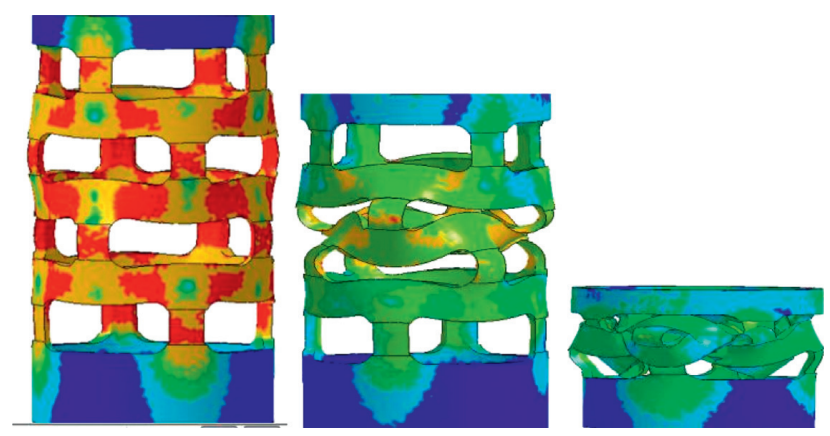

(e)

FIGURe 4: Compression and the buckling deformation process of each scheme member. (a) Buckling deformation process of YG-1, (b) buckling deformation process of YG-2, (c) buckling deformation process of YG-3, (d) buckling deformation process of YG-4, and (e) buckling deformation process of YG-5.

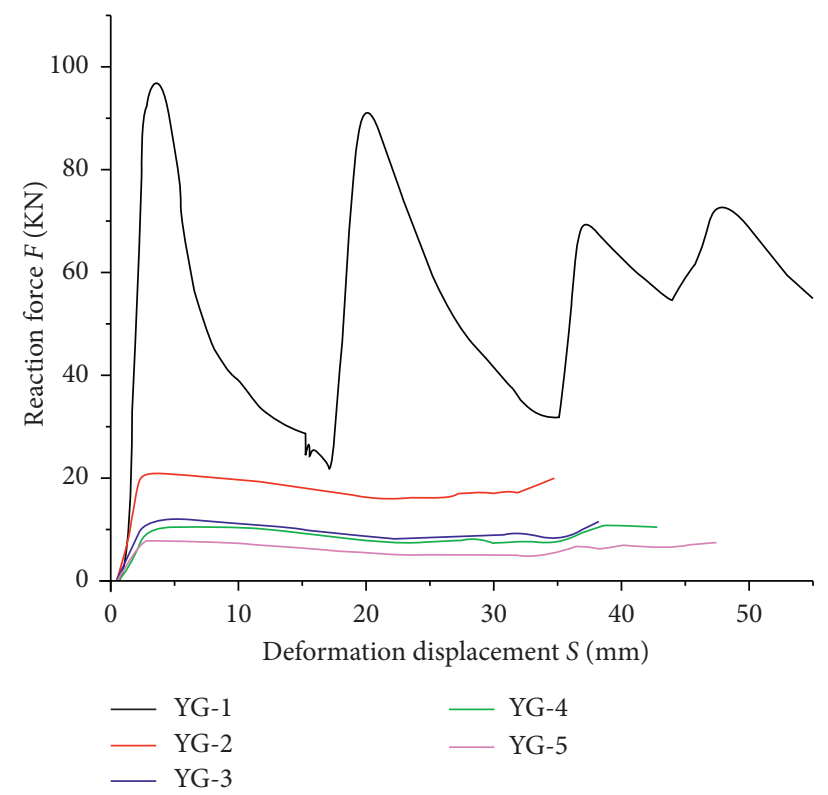

FIGURE 5: Support reaction force-deformation curve for simulation of crushing and buckling of thin-walled circular tube members with different schemes.

bending wrinkles and deflection deformation. Components YG-2 and YG-3 without induction groove lack the guiding effect of the induction groove in the process of crushing and buckling deformation and are prone to irregular deformation. After the component is compressed and deformed, it expands around and takes up other space. Component YG-5 is set to induce, and the groove makes the crushing and buckling deformation more stable and regular.

4.2. Performance Parameters of Thin-Walled Round Pipe Crushed Components. The reaction force-deformation curve of the crushing buckling test of each member is shown in Figure 10. The main conclusion is as follows:

(1) The reaction force-deformation curve of the crushing buckling test is basically consistent with the simulation curve. According to the test data, it shows that the reaction force-deformation curve of each component also has three similar stages.

(2) According to the testing of the five components, generally, the thinner the wall thickness of the component, the lower the overall level of the reaction force during the crushing buckling process, which is consistent with the simulation results.

(3) The arrangement of the inducing groove can make the crushing and buckling deformation more stable and regular, which can effectively reduce the initial peak load, reduce the distance of the elastic stage, and increase the effective deformation pressure stroke. It is consistent with the simulation results.

On the basis above, the various evaluation parameters of the crush buckling test of the four components are analyzed 


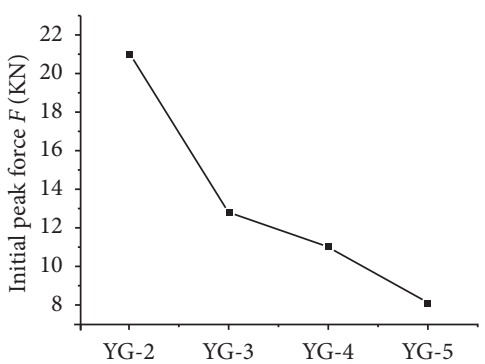

Thin-walled round pipe component scheme

-- Thin-walled hollow tube emulation

(a)

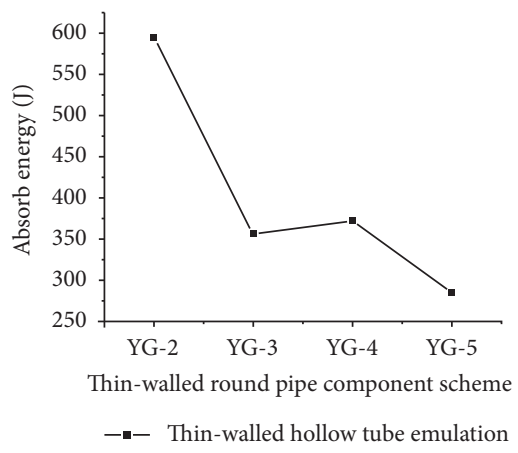

(d)

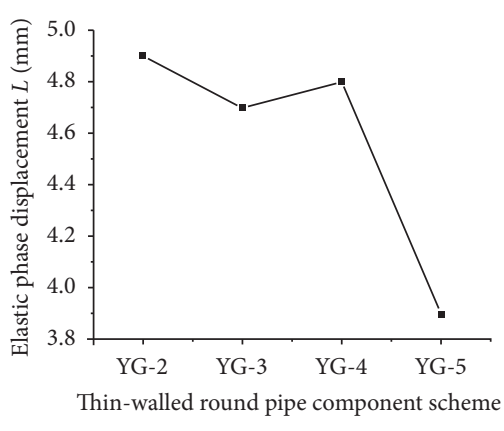

-- Thin-walled hollow tube emulation

(b)

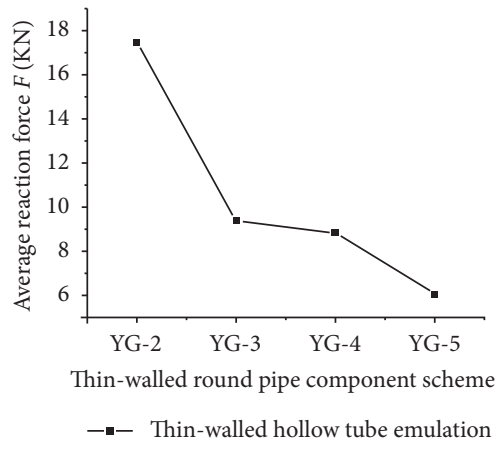

(e)

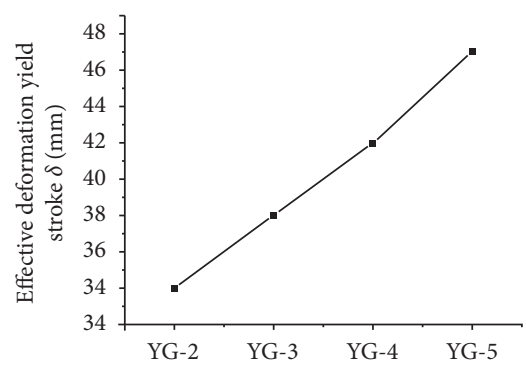

Thin-walled round pipe component scheme

- - Thin-walled hollow tube emulation

(c)

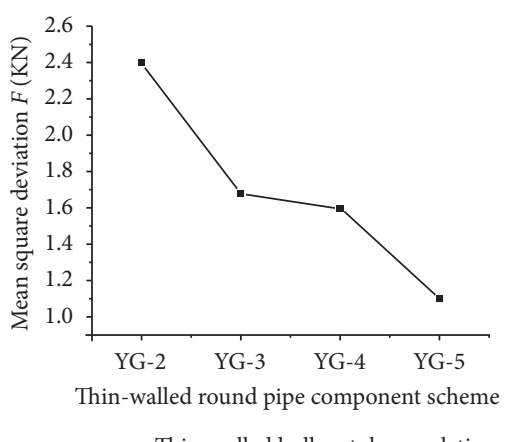

(f)

Figure 6: Performance evaluation parameters of the simulation of component crushing and buckling of various schemes. (a) Initial peak force, (b) displacement during the elastic stage, (c) effective deformation yield stroke, (d) total absorbed energy, (e) average reaction force, and (f) mean square deviation.

TABLE 2: Performance evaluation parameters of thin-walled round pipes without hollowing out.

\begin{tabular}{lcc}
\hline Number & Initial peak force $(\mathrm{KN})$ & Yielding distance of elastic deformation $(\mathrm{mm})$ \\
\hline YG-1 & 95 & 3.1 \\
\hline
\end{tabular}
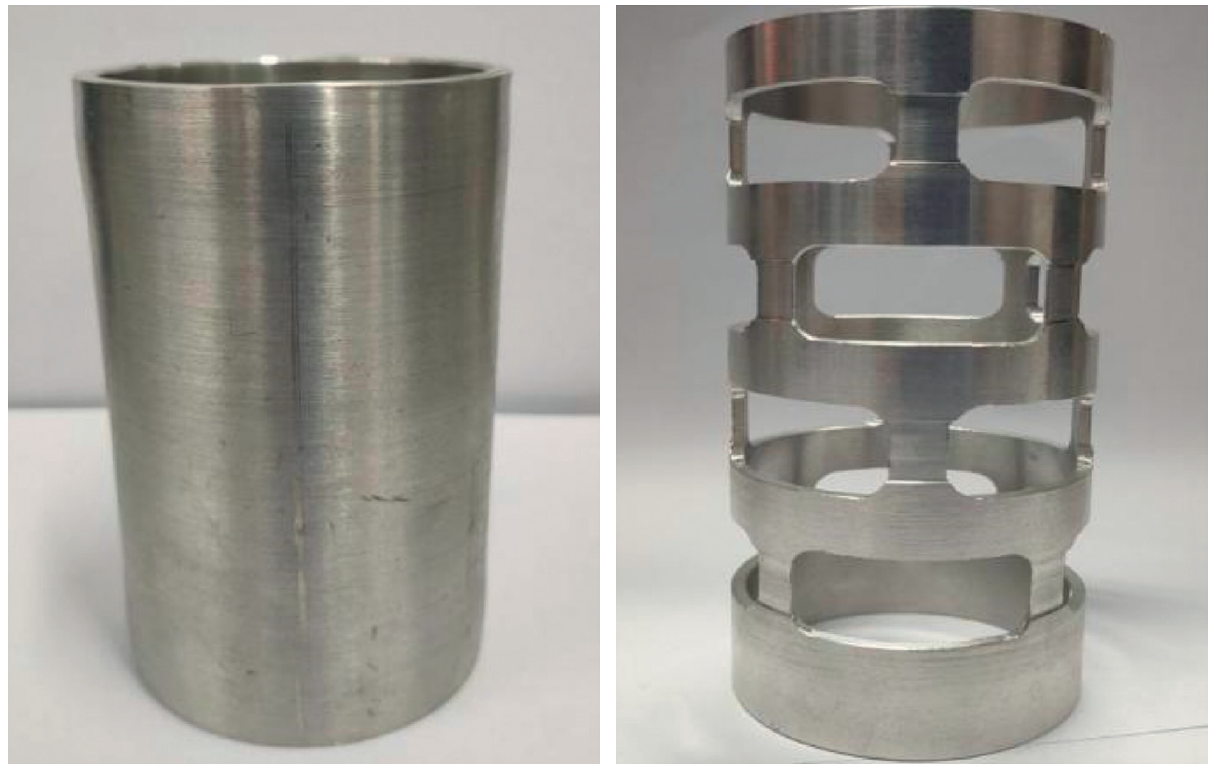

FIGURE 7: Thin-walled round tube crushing component. 


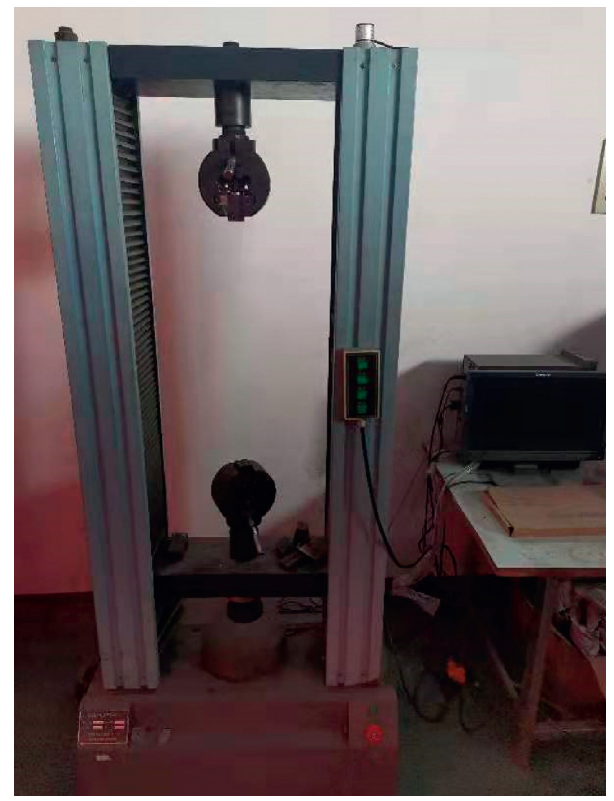

FIGURE 8: Microcontrol electronic universal testing machine.

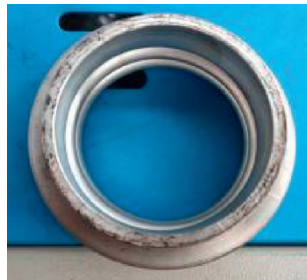

YG-1

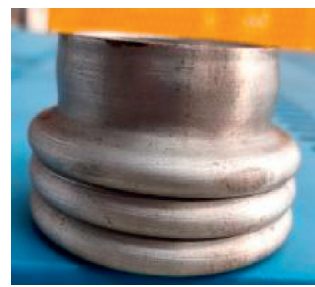

YG-1

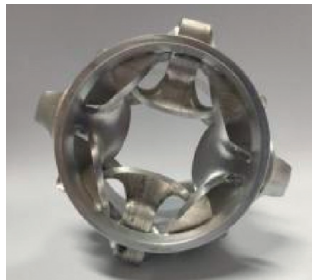

YG-2

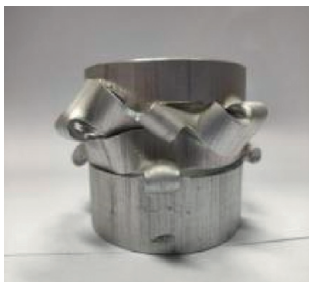

YG-2

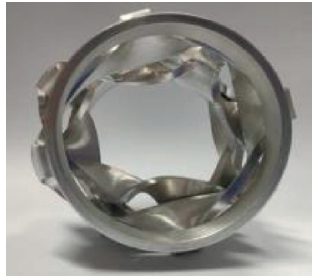

YG-3

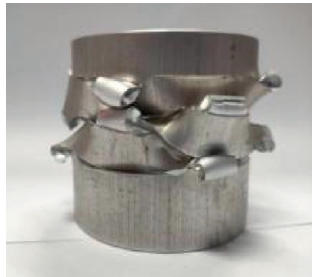

YG-3

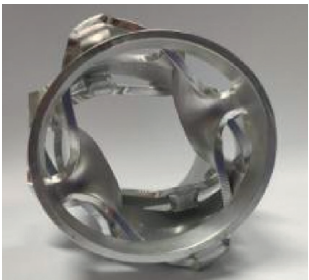

YG-4

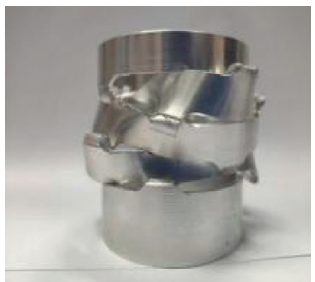

YG-4

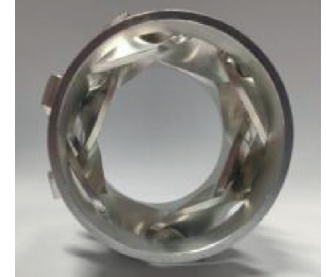

YG-5

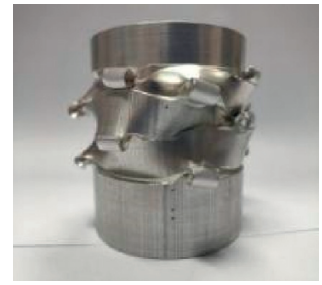

YG-5

FIGURE 9: Deformation morphology of components in the crushing buckling test.

(the Euler instability of the circular tube component YG-1 is no longer considered).

With the changes of the structure, wall thickness, and induced groove thickness of the components, the effect of related parameters is obtained and is compared with simulation results above, which is shown in Figure 11.

In general, the analysis result is the same as that described in the simulation analysis, which verifies the 


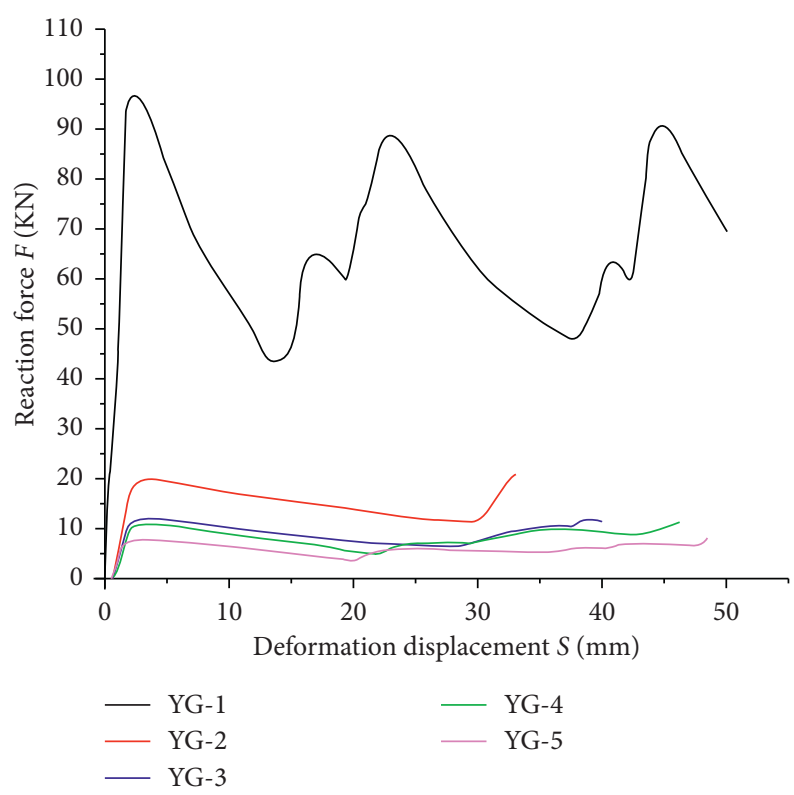

FIgURE 10: The reaction force-deformation curve of the compression buckling test.

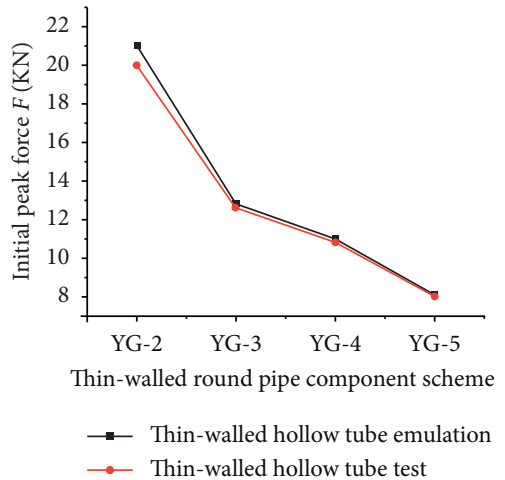

(a)

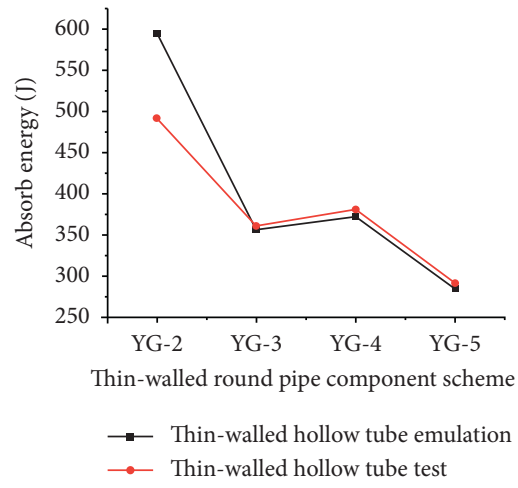

(d)

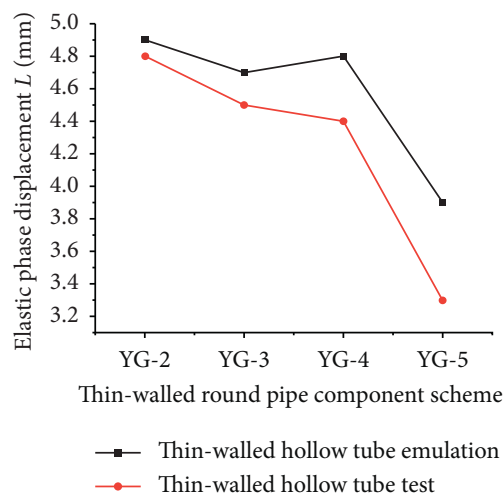

(b)

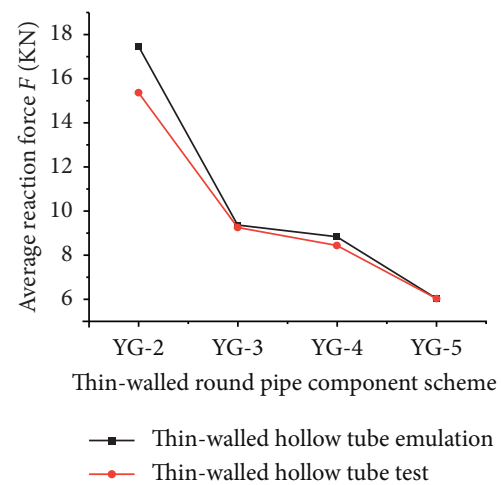

(e)

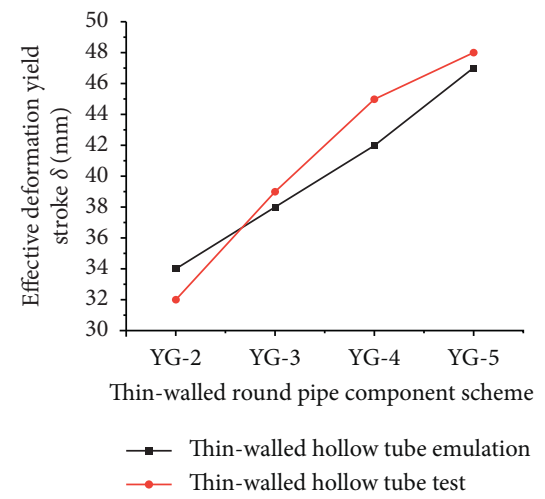

(c)

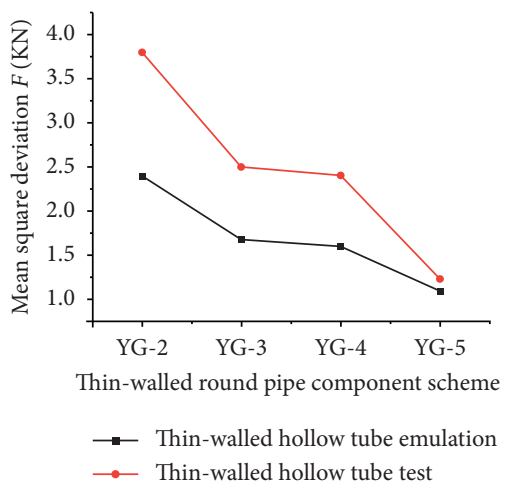

(f)

FIGURE 11: The performance evaluation parameters of the crushing buckling test and simulation of each scheme member. (a) Initial peak force, (b) elastic phase displacement, (c) effective deformation yield stroke, (d) absorb energy, (e) average reaction force, and (f) mean square deviation. 
reliability of the simulation model and provides an important model basis for subsequent research.

\section{Conclusion}

(1) Without changing the material of the thin-walled tube, the thickness, and cross-sectional shape provided, inducing structure can ensure more stable and regular deformation and reduce the initial peak load. The arrangement of the hollow structure is effective to inhibit the annular mode deformation and Eulerian instability of collapse buckling of ordinary tubular members, which make the components tend to be stable. According to the simulation, it shows that the hollow structure crushing tube has better reaction fluctuation performance comparing with the ordinary tube. In the actual test, Euler instability occurs in the ordinary round pipe components, which results in the loss of effective crushing and antiscour performance.

(2) According to the simulation and experiment, it shows that for the hollow structure of thin-walled round pipes, as the wall thickness of the thin-walled round pipe decreases, the initial peak force and the displacement in the elastic phase decrease, the effective deformation yield distance increases, the total energy absorption and the average support reaction force decrease, and the mean square deviation of the reaction force is reduced.

(3) The opening of the induction groove makes the component's crushing and buckling deformation more stable and regular and can effectively reduce the initial peak force and the elastic phase displacement, increase the effective deformation yield distance, and improve the stability during the component's antishock process.

(4) The test result is consistent with the simulation result, which verifies the reliability of the simulation model and provides an important model basis for the future work.

\section{Data Availability}

The data used to support the findings of this study are available from the corresponding author upon request.

\section{Conflicts of Interest}

The authors declare that they have no conflicts of interest.

\section{References}

[1] T. Lan, Analysis of Dynamic Conditions of Rock Burst in Datai Well and Research on Prevention Technology, Liaoning Technical University, Fuxin, China, 2011.

[2] X. Du, Y. Wang, and L. Yang, "Analysis of 4 typical rock burst accidents from 2011 to 2013 in China," Safety in Coal Mines, vol. 46, no. 1, pp. 183-189, 2015.

[3] G. Zhang, C. Zang, M. Chen et al., "Ground response of entries driven adjacent to a retreating long wall panel,"
International Journal of Rock Mechanics and Mining Sciences, vol. 138, 2021.

[4] Z. Li, S. Zhang, W. Cao et al., "Development and application of anti-bumping gateway hydraulic powered support," Coal Science and Technology, vol. 35, no. 1, pp. 54-58, 2007.

[5] Z. Yu and W. Guan, "Take comprehensive measures and use the anti-roadway antidumping gateway hydraulic powered support to ensure the safety production of severe rock burst area," Opencast Mining Technology, vol. 5, no. 5, pp. 81-84, 2013.

[6] C. Wang, Anda, C. Han et al., "Simulation and test of a new type of ribbed plate cylindrical energy-absorbing and antiimpact component under rock impact," Vibration and Shock, vol. 38, no. 11, pp. 23-210, 2019.

[7] J. Yang, Z. Tang, F. He et al., "Energy absorption and antiimpact properties of mine diameter-expanding energy absorption components," Journal of Vibration and Shock, vol. 34, no. 8, pp. 134-138, 2015.

[8] Z. Tang, Y. Pan, X. Hu et al., "Numerical analysis on properties of inside-outside overturning energy absorption and anti-impact components of hydraulic column," Journal of Safety Science and Technology, vol. 11, no. 7, pp. 74-79, 2015.

[9] Y. Pan, Y. Xiao, G. Li et al., "Design of a buffer device for absorbing waves and energy in mining and its primary experiments," Chinese Journal of Rock Mechanics and Engineering, vol. 31, no. 4, pp. 649-655, 2012.

[10] X. Ma, Y. Pan, J. Zhang et al., "Influence of plate inclination angle on energy absorption characteristics of pre-folded edge tube anti-scour and supporting device," China Safety Science Journal, vol. 27, no. 1, pp. 122-127, 2017.

[11] Z. Tang, Y. Pan, Q. Li et al., "Numerical analysis of energyabsorption properties of a thin-walled component with square folds for rock burst prevention in mine," Journal of Vibration and Shock, vol. 33, no. 23, pp. 87-91, 2014.

[12] F. Li, K. Zhang, and J. Wen, "Numerical study on energy absorption characteristics of axial crushing of thin-walled circular tubes with multiple arc grooves," Ordnance Industry Automation, vol. 36, no. 2, pp. 80-85, 2017.

[13] S. M. Hosseini and M. Shariati, "Experimental analysis of energy absorption capability of thin-walled composite cylindrical shells by quasi-static axial crushing test," ThinWalled Structures, vol. 125, pp. 259-268, 2018.

[14] S. Montazeri, M. Elyasi and A. Moradpour, "Investigating the energy absorption, SEA and crushing performance of holed and grooved thin-walled tubes under axial loading with different materials," Thin-Walled Structures, vol. 131, pp. 646-653, 2018.

[15] R. Shams, A. Niknejad, A. Ghani Olabi, and M. Zamani Nejad, "Quasi-static flattening energy absorption process on preformed circular tubes by numerical and experimental analyses," Thin-Walled Structures, vol. 144, 2019.

[16] J. Song, S. Xu, L. Xu, J. Zhou, and M. Zou, "Experimental study on the crashworthiness of bio-inspired aluminum foam-filled tubes under axial compression loading," ThinWalled Structures, vol. 155, 2020.

[17] S. Dong and X. Chu, "Design and analysis of energy-absorbing and anti-scouring support components of mine bolts," Coal Mine Machinery, vol. 41, no. 11, pp. 62-64, 2020.

[18] R. Yao, Z. Zhao, G. Yin, and B. Zhang, "Theoretical study of thin-walled circular pipes with openings under axial load," Vibration and Shock, vol. 39, no. 2, pp. 141-147, 2020.

[19] Z. Li, S. Wenbin, S. Rakheja, J. Liu, M. Tan, and W. Ahmed, "Research on the influence of induced structure on the axial 
crushing characteristics of thin-walled square tubes filled with aluminum foam," Vibration and Shock, vol. 39, no. 6, 2020.

[20] Z. Yi, Y. Yao, G. Gao, and D. Liu, "Research on buckling mode and initial peak force control of thin-walled square tubes under axial impact," Journal of Railway Science and Engineering, vol. 17, no. 7, pp. 1841-1848, 2020.

[21] C. Wang, Y. Liu, G. Miao et al., "Design and simulation of a multi head screw hydraulic -buffer," Chinese Hydraulicsand Pneumatics, no. 9, pp. 48-55, 2020.

[22] E. Zhu, P. Mandal, and C. R. Calladine, "Analysis of bucking of thin cylindrical shells under axial compression," China Civil Engineering Journal, vol. 34, no. 3, pp. 18-22, 2001.

[23] General Administration of Quality Supervision, Inspection and Quarantine of the People's Republic of China, The Second Part of Hydraulic Supports for Coal Mines: Technical Requirements for Columns and Jacks: GB25974. 2-2010, National Standardization Administration of China, Beijing, China, 2011.

[24] General Administration of Quality Supervision, Inspection and Quarantine of the People's Republic of China, The Third Part of Hydraulic Support for Coal Mine: Hydraulic Control System and Valve: GB 25974.2-2010, China National Standardization Administration, Beijing, China, 2011.

[25] Z. Tang, Y. Pan, X. Zhu et al., "Analysis on energy absorption and impact prevention features of hexagonalthin-wall component under radial compression," Coal Science and Technology Coal Sci Technol, vol. 44, no. 11, pp. 56-61, 2016.

[26] W. Abramowicz and N. Jones, "Dynamic axial crushing of square tubes," International Journal of Impact Engineering, vol. 2, no. 2, pp. 179-208, 1984.

[27] W. Abramowicz and N. Jones, "Dynamic progressive buckling of circular and square tubes," International Journal of Impact Engineering, vol. 4, no. 4, pp. 243-270, 1986.

[28] B. P. Dipaolo, P. J. M. Monteiro, and R. Gronsky, "Quasistatic axial crush response of a thin-wall, stainless steel box component," International Journal of Solids and Structures, vol. 41, no. 14, pp. 3707-3733, 2004.

[29] Ø. Jensen, M. Langseth, and O. S. Hopperstad, "Experimental investigations on the behaviour of short to long square aluminium tubes subjected to axial loading," International Journal of Impact Engineering, vol. 30, no. 8-9, pp. 973-1003, 2004.

[30] J. M. Alexander, "An approximate analysis of the collapse of thin cylindrical shells under axial loading," The Quarterly Journal of Mechanics and Applied Mathematics, vol. 13, no. 1, pp. 10-15, 1960.

[31] A. Pugsley and M. Macaulay, "The large-scale crumpling of thin cylindrical columns," The Quarterly Journal of Mechanics and Applied Mathematics, vol. 13, no. 1, pp. 1-9, 1960. 